\title{
BIODIESEL DE ÓLEO RESIDUAL DE FRITURA: UMA OPORTUNIDADE BIOENERGÉTICA PARA O ESTADO DE ALAGOAS
}

\section{ARTIGO ORIGINAL}

SILVA, Alex Aguiar da ${ }^{1}$

SANTOS, Pablo Rodrigo Moura ${ }^{2}$

SILVA, Alex Aguiar da. SANTOS, Pablo Rodrigo Moura. Biodiesel de óleo residual de fritura: Uma oportunidade bioenergética para o Estado de Alagoas. Revista Científica Multidisciplinar Núcleo do Conhecimento. Ano 05, Ed. 04, Vol. 04, pp. 128 140. Abril de 2020. ISSN: 2448-0959, Link de acesso: https://www.nucleodoconhecimento.com.br/meio-ambiente/oleo-residual

\section{RESUMO}

A crescente demanda energética aliada a necessidade de diversificação e utilização de fontes renováveis são questões cada vez mais evidentes nos centros de discussão. Não obstante, os problemas ambientais causados pelo descarte incorreto de resíduos no meio ambiente têm chamado a atenção, especialmente pelas consequências nefastas que tal ação tem promovido. Essas temáticas podem ser aplicadas à realidade do estado de Alagoas, cuja matriz energética é oriunda, em grande parte, de fontes renováveis, no entanto, há uma grande preponderância da exploração do setor sucroalcooleiro, o que revela uma forte dependência econômica e energética dessa monocultura. Nessa perspectiva, o presente artigo pretende abordar essa problemática, propondo como alternativa a produção de biodiesel a partir do óleo residual de fritura, uma alternativa viável tanto economicamente quanto ecologicamente, além de possuir potencial para criação de novos empregos e renda

${ }^{1}$ Mestre em Energia da Biomassa; Bacharel em Engenharia Mecânica; Técnico em Automobilística.

2 Pós-graduação em Direito Administrativo e Graduação em Agronomia. 
para o estado. Esse biocombustível possui características muito similares ao diesel convencional, porém renováveis, e, quando produzido através da reutilização do óleo de fritura, poderá causar impactos ambientais muito positivos, especialmente para Alagoas.

Palavras-chave: Biodiesel, Alagoas, óleo de fritura.

\section{INTRODUÇÃO}

Não é de hoje que a humanidade tem se servido da utilização de energia oriunda, principalmente, de combustíveis fósseis. Hoje, o petróleo e seus derivados são, inegavelmente, a maior fonte primária de energia do planeta. Apesar disso, seu caráter finito aliado a repercussão nociva do seu consumo ao meio ambiente tem despertado a preocupação de especialistas e pesquisadores na busca de novas alternativas energéticas.

Nesse atual cenário, os biocombustíveis têm se afirmado como uma solução promissora para esta problemática. Destaca-se, dentre outros, o biodiesel que, por definição, é um substituto natural e renovável do diesel comum, e pode ser produzido a partir da transesterificação de óleos vegetais, gorduras animais e óleos utilizados para a cocção de alimentos (óleos de fritura), o que confere a ele características ecológicas que alcançam toda a sua produção até a sua utilização (RAMOS et al., 2003).

No Brasil, seja por falta de uma consciência ambiental ou em razão do sério problema de saneamento enfrentado pela grande maioria dos municípios brasileiros, boa parte dos rejeitos decorrentes do consumo humano de óleos vegetais são despejados na rede de esgoto e em mananciais sem o menor tratamento, fato que se configura um relevante problema ambiental por vários motivos, os quais podemos destacar, dentre outros, a sua relação com a emissão de metano na atmosfera - reconhecido agente causador do efeito estufa - e o entupimento de encanamentos e vias sanitárias, obstruindo a passagem de resíduos sólidos. Vale ressaltar que cada litro de óleo despejado tem o potencial de contaminar até 1.000 tanques de 500 litros de água, em 
razão da sua baixa solubilidade, desregulando as taxas de oxigênio e provocando, desta forma, a morte de peixes e outras espécies (GUERRERO-ROMERO; SIERRA, 2011; “Sabesp”, 2019)

Essa realidade também é vivida no estado de Alagoas, agravada pela necessidade de proteção ambiental em razão do seu forte apelo turístico e infinidades em belezas naturais. O meio ambiente alagoano precisa ser protegido, pois é um ativo do estado, além de ser o responsável por fornecer empregos diretos na área de turismo, setor este classificado como o quarto segmento econômico que mais emprega no estado (FAZENDA, 2017).

A utilização desses rejeitos como matéria-prima para a fabricação de biodiesel, portanto, seria uma alternativa duplamente sustentável, pois diminuiria a emissão desse óleo no meio ambiente e, ao mesmo tempo, colaboraria para a produção de um combustível atestadamente renovável e biodegradável, além de se estabelecer como uma nova oportunidade empregatícia, principalmente para uma região onde há uma baixa taxa de empregabilidade como é o estado de Alagoas. (IBGE, 2012)

Mediante o exposto até aqui, o presente artigo se propõe a abordar a produção do biodiesel a partir da utilização do óleo de fritura como matéria-prima e a viabilidade da sua implantação na realidade do estado de Alagoas, discutindo-a como uma alternativa rentável e sustentável para a região.

\section{METODOLOGIA}

\subsection{A HISTÓRIA DO BIODIESEL NO BRASIL}

O interesse brasileiro no desenvolvimento de combustíveis renováveis surgiu a partir da crise energética mundial dos anos 70 , com a criação do Programa Nacional do Álcool (Pró-Álcool), visando estimular a produção deste combustível a fim de diminuir a dependência das importações de petróleo (PLÁ, 2002). Além do Pró-Álcool, também houve no Brasil outras iniciativas como o Pró-Óleo, criado pelo governo federal nos anos de 1970, com o intuito de substituição dos combustíveis fósseis. O Pró-Óleo 
visava a adição de óleos vegetais e seus derivados ao óleo diesel em 30 \%, com a perspectiva de substituição total em longo prazo. Mas esse programa, diferentemente do Proálcool, foi completamente abandonado em 1986 devido à normalização nos preços do petróleo (PINHO; SUAREZ, 2017).

Com a nova alta do petróleo em 2008 e 2009, quando o preço do barril chegou a atingir 140 dólares, o questionamento a respeito de fontes alternativas de energia ganhou força no cenário mundial. Nota-se que, durante um bom tempo na história nacional e internacional, a discussão sobre a procura por novas fontes energéticas renováveis sempre dependia de alguma oscilação no mercado internacional do petróleo, porém, nos últimos anos, independente dessas oscilações, esse interesse tem se mostrado consolidado, sendo visto por muitos países como uma questão estratégica para a manutenção do desenvolvimento e segurança nacional (DOMINGOS, 2010).

O biodiesel foi oficialmente introduzido na matriz energética brasileira através da Medida Provisória $n^{\circ}$ 214, de 13 de setembro de 2004, convertida posteriormente na Lei $\mathrm{n}^{\circ}$ 11.097, de 2005. Esta mesma MP delegava atribuições e competências à Agência Nacional do Petróleo (ANP) para regular, promover, contratar, fiscalizar e autorizar as atividades de produção, estocagem, distribuição e revenda do biodiesel (BRASIL, 2004).

Logo em seguida, o governo brasileiro instituiu o Programa Nacional de Produção e Uso de Biodiesel (PNPB), objetivando principalmente fortalecer a produção do biodiesel, levando em consideração o enorme potencial que o país possuía para suprir as crescentes demandas por combustíveis renováveis no cenário internacional, além de criar mecanismos de fomento à inclusão social no meio rural, agregando a participação da agricultura familiar na cadeia do biocombustível, diversificando as matérias-primas e promovendo o desenvolvimento regional. Para que fosse assegurada a inclusão social prometida, o PNPB criou ferramentas como isenções fiscais, subsídios financeiros, créditos específicos e o Selo Combustível Social, sendo este último um certificado concedido às empresas de biodiesel que adquirem parte de 
sua matéria-prima de agricultores familiares (DE SOUZA et al., 2016; FINCO; DOPPLER, 2011).

Além disso, a Lei n 11.097/05 determinou que, entre o ano de 2005 até o final do ano de 2007, fosse adicionado a mistura de $2 \%$ de biodiesel (B2) ao diesel mineral, em caráter experimental, facultativamente. Esse percentual tornou-se obrigatório a partir de 2008, evoluindo nos anos seguintes, de acordo com critérios estipulados pelo Conselho Nacional de Políticas Energéticas (CNPE). A Figura 1 ilustra bem essa evolução, correlacionando-a com a produção do biocombustível $\left(\mathrm{m}^{3}\right)$ :

Figura 1: Evolução do percentual de mistura do biodiesel ao diesel comum e os impactos no mercado

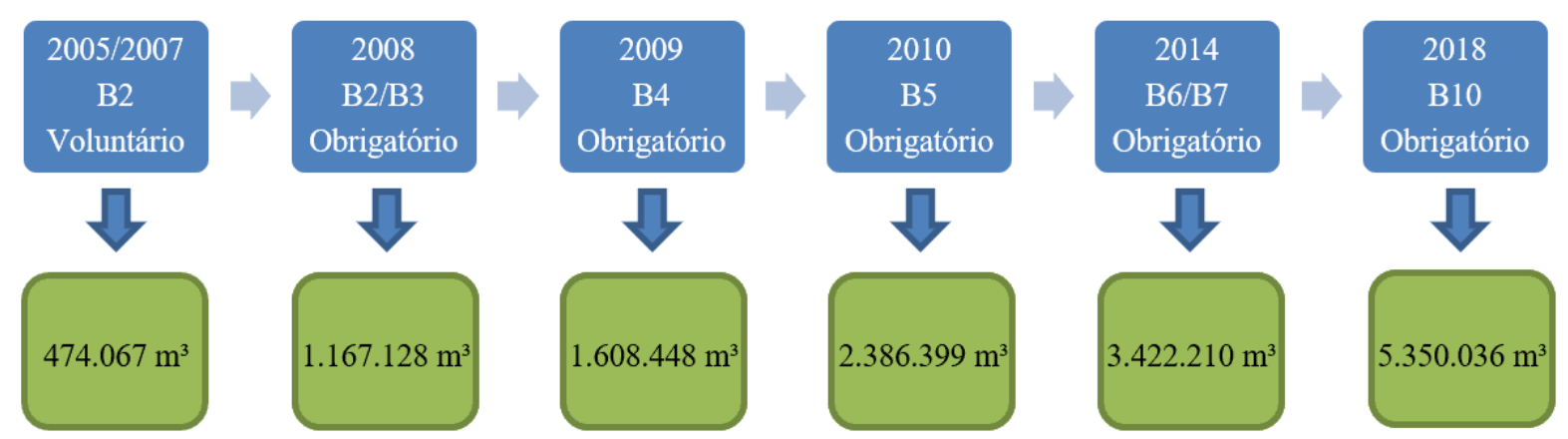

Fonte: (ANP, 2019a)

É possível observar, na Figura 1, que a produção de biodiesel teve um aumento significativo no período, em compasso com o aumento do percentual das misturas B's ao diesel mineral. Entretanto, esses índices tiveram pouco impacto nas importações do petrodiesel, que oscilou durante esses anos (ANP, 2019b). Isso demonstra que, apesar da preocupação em fomentar a cadeia produtiva desse biocombustível no Brasil, os resultados ainda não se refletiram como uma mudança significativa na substituição dos combustíveis fósseis. 


\subsection{MAPA ENERGÉTICO E CENÁRIO ECONÔMICO DO ESTADO DE ALAGOAS}

De acordo com o Balanço Energético de Alagoas em 2018 - Ano Base 2017 (BEAL, 2018), o estado de Alagoas obteve uma produção de energia primária de 2.349 mil toneladas de equivalente de petróleo (tep). Boa parte dessa produção está fundamentada basicamente em recursos renováveis, como os derivados da cana de açúcar e energia hidráulica. A Tabela 1 demonstra todas as fontes de energia que compõem a matriz energética alagoana.

Tabela 1: Produção de energia primária em Alagoas

\begin{tabular}{|l|l|l|}
\hline Fonte de Energia & Valores em $10^{3}$ tep & Valores em \% \\
\hline NÃO RENOVÁVEL & $\mathbf{5 5 7}$ & $\mathbf{2 3 , 7 2}$ \\
\hline Petróleo & 168 & $\mathbf{7 , 1 6}$ \\
\hline Gás Natural & 389 & 16,56 \\
\hline RENOVÁVEL & $\mathbf{1 . 7 9 2}$ & $\mathbf{7 6 , 2 8}$ \\
\hline Energia Hidráulica & 533 & 22,69 \\
\hline Caldo de Cana & 90 & 3,85 \\
\hline Bagaço de Cana & 1.024 & 43,61 \\
\hline Melaço de Cana & 136 & 5,78 \\
\hline Lenha & 8 & 0,36 \\
\hline TOTAL & $\mathbf{2 . 3 4 9}$ & $\mathbf{1 0 0 , 0 0}$ \\
\hline
\end{tabular}

Fonte: BEAL, 2018 
Figura 2: Produção de energia primária em Alagoas

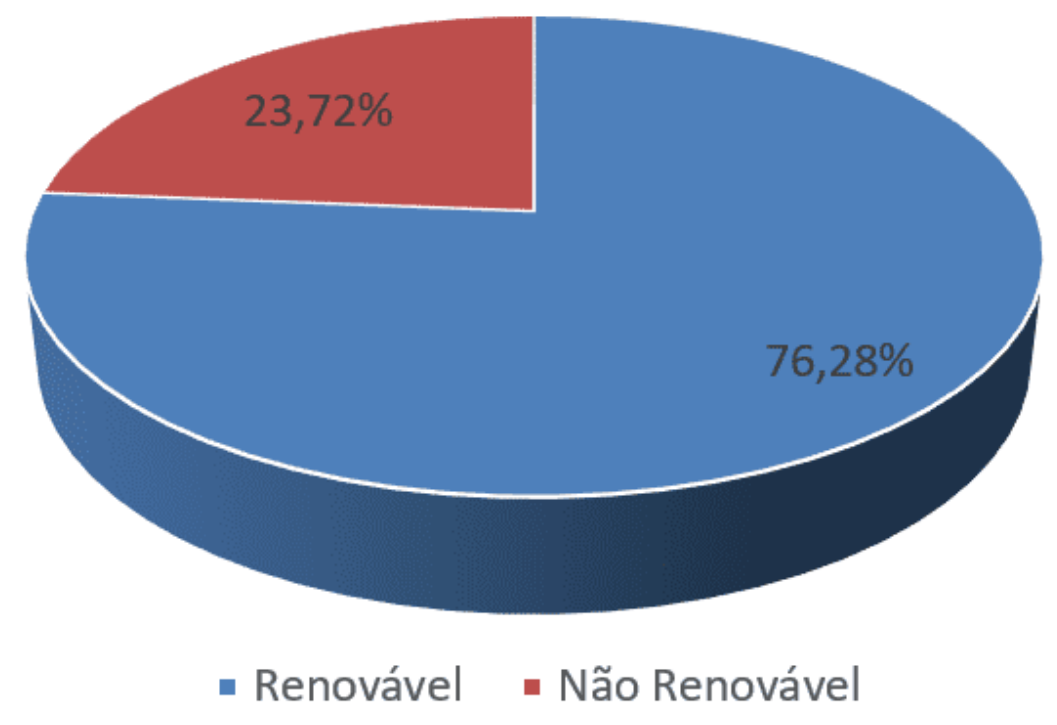

Fonte: BEAL, 2018

Podemos observar, de acordo com a Figura 2, que mais de três quartos da matriz energética de Alagoas provém de fontes renováveis, o que demonstra uma preocupação em se produzir energia limpa. No entanto, não há uma diversificação, pois cerca de $69,75 \%$ dessas fontes renováveis são provenientes diretamente ou indiretamente da indústria sucroalcooleira, escancarando a dependência do estado nesse segmento econômico que, em momentos de crise, poderá causar alguma repercussão energética negativa. A Figura 3 destaca a produção da cana-de-açúcar em Alagoas, desde a safra 2005/2006 até a safra 2018/2019, evidenciando a oscilação produtiva do setor (CONAB, 2019). 
Figura 3: Série histórica da produção de cana-de-açúcar no estado de Alagoas

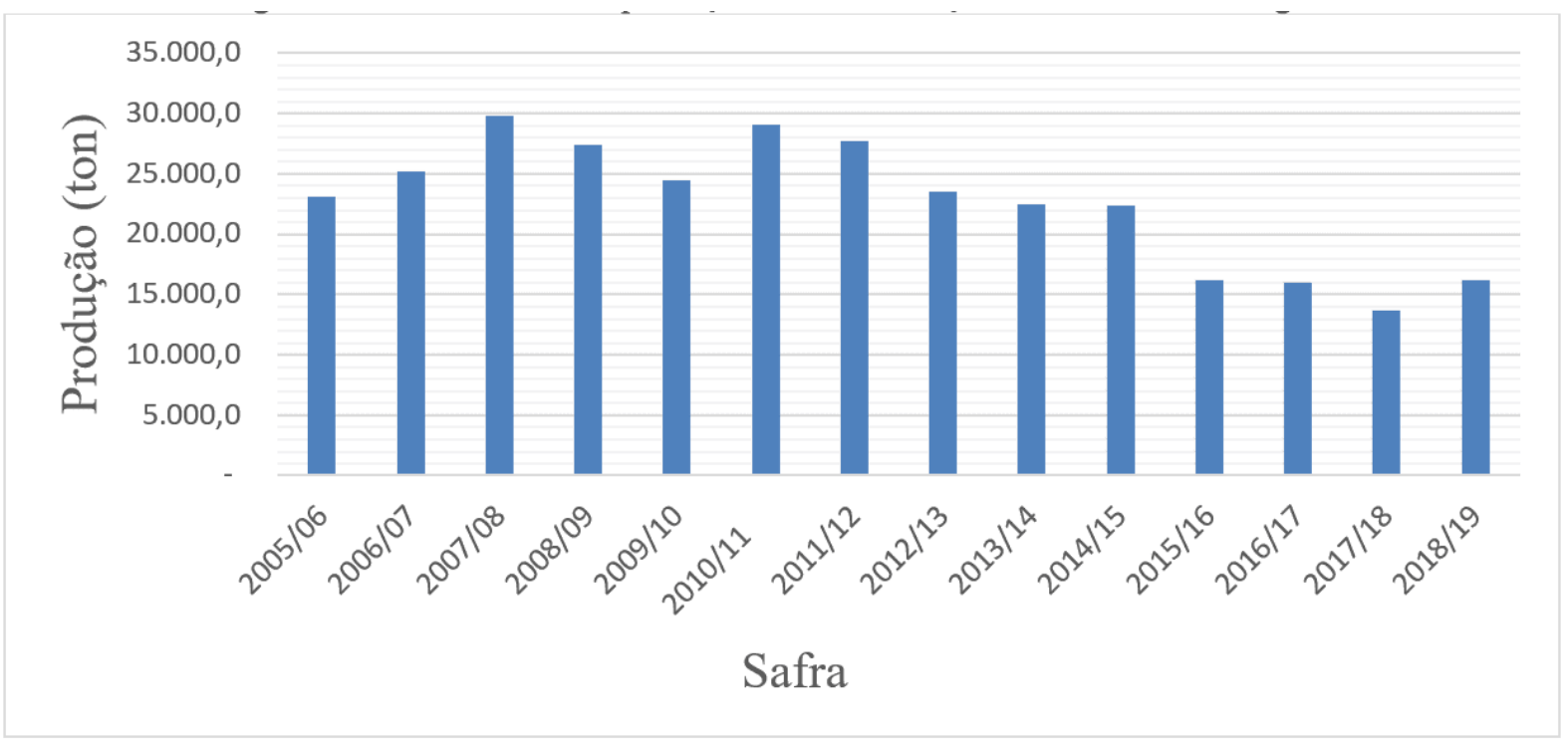

Fonte: CONAB, 2019

Nesse particular, é forçoso fazer uma reflexão profunda sobre a monocultura da canade-açúcar no estado de Alagoas. O início da sacaricultura alagoana remonta ao período áureo da cultura no Brasil, mais especificamente, no século XVI, quando ainda era um território anexo a Pernambuco. A partir da década de 1970, com o programa PLANALÇÚCAR e, mais especificamente, na década de 80, com o PROÁLCOOL, houve um grande incentivo para a construção de destilarias, o que gerou, por consequência, uma maior necessidade de expansão da área cultivada. As ações desses dois programas trouxeram implicações nefastas ao meio ambiente do estado que podem ser observadas nos dias atuais, como o avanço da fronteira agrícola e, por conseguinte, a redução da cobertura vegetal original, causando o empobrecimento nutricional do solo, além do aumento da concentração fundiária com a aquisição de propriedades de pequeno e médio porte pelo setor, consolidando o sistema monocultor (SANTOS; PEREIRA; ANDRADE, 2007). Hoje, infelizmente, seja por pressão dos grandes produtores ou por uma mentalidade ultrapassada ou conveniente, o estado se mantém refém dessa monocultura, deixando de focalizar em outras alternativas econômicas e energéticas. 
Estratificando o consumo de energia do estado por setor, Alagoas tem, como segmento líder, o setor de transporte, correspondendo a 33,84\% de toda anergia consumida no ano de 2017. Desta forma, verifica-se que a demanda por combustíveis no estado é de imensa necessidade para manter a rede de transportes em pleno funcionamento. A Figura 4 ilustra como está dividido o consumo energético do estado.

Figura 4: Consumo de energia por setor no estado de Alagoas no ano de 2017

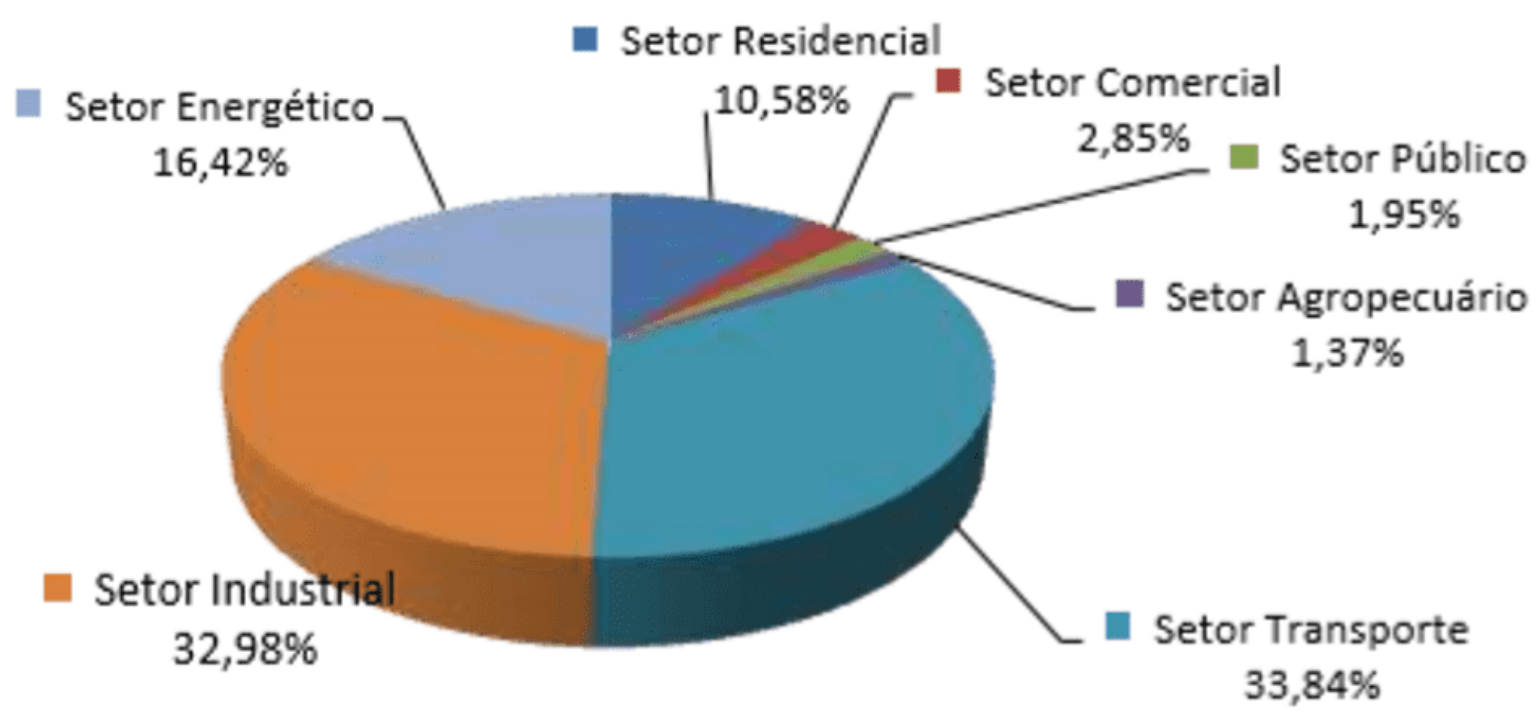

Fonte: BEAL, 2018

Em relação à economia alagoana, a perspectiva é de um crescimento do Produto Interno Bruto (PIB) para o ano de 2018, variando em 1,53\% em relação a 2017. Os setores de Agropecuária e Serviços foram os principais responsáveis pelo ganho positivo, destoando do setor industrial que apresentou recuo (ÁVILA, 2019).

No que tange aos dados relacionados ao emprego, segundo o Instituto Brasileiro de Geografia e Estatística (IBGE), no segundo trimestre do ano de 2019, o estado de Alagoas apresentou uma taxa de desocupação de 14,6\%. Trata-se do sétimo maior índice de desemprego entre as 27 unidades da federação e o quarto maior da região Nordeste. Ainda segundo o IBGE, no mesmo período de 2019, Alagoas obteve a segunda maior taxa de pessoas desalentadas do país (aquelas que desistiram de 
procurar emprego), com 15,2\%, ficando atrás apenas do Maranhão, com 18,4\% (IBGE, 2019) 5 .

Logo, sendo a indústria sucroalcooleira a responsável pela maior parte de energia produzida no estado e, atrelado a isso, as altas taxas de desemprego e uma crescente demanda energética no setor de transportes, percebe-se uma fenda nesse discurso que nos leva, inegavelmente, a compreender a carência existente para que seja disponibilizada novas fontes energéticas para produção de combustível no estado de Alagoas, de forma a retirar o estado de uma situação delicada, ao depender, quase que exclusivamente, do setor sucroalcooleiro. Somado a isso, essas novas fontes energéticas seriam responsáveis pela injeção de empregos diretos e indiretos no estado, alavancando, de forma positiva, os índices que corroboram para uma boa avaliação econômica e empregatícia do estado.

\subsection{PRODUÇÃO DE BIODIESEL A PARTIR DE ÓLEO DE FRITURA}

Silva (1997) descreve o biodiesel como um combustível 100\% renovável, usado como alternativa ao diesel mineral em qualquer motor de ignição por compressão (motor a diesel), necessitando de pouca ou nenhuma alteração mecânica em sua estrutura, além de manter a mesma performance e rendimento.

Quimicamente, de acordo com a ASTM (American Society for Testing and Materials Standard) (2019), apresenta estrutura molecular de um éster monoalquil de ácidos graxos de cadeia longa e é produzido a partir de óleo vegetal, gordura animal ou óleos residuais em uma reação química conhecida como transesterificação, onde um triglicerídeo reage com um álcool, na presença de um catalisador ácido ou básico, resultando em um éster metílico ou etílico (biodiesel) - a depender do tipo de álcool utilizado na reação - e glicerina (PARENTE, 2003).

Além de renovável e biodegradável, o biodiesel puro (B100) possui características importantes, como ser um combustível livre de enxofre, além de reduzir em até $48 \%$ as emissões de monóxido de carbono, $67 \%$ de hidrocarbonetos não-queimados e $47 \%$ 
de material particulado (OLIVEIRA; SUAREZ; SANTOS, 2008). Costa Neto et. al. (2000) aponta outras características complementares, conforme Tabela 2:

Tabela 2: Propriedades complementares atribuídas ao biodiesel em comparação ao óleo diesel comercial.

\begin{tabular}{l|l|} 
Características & Propriedades complementares \\
Características químicas & $\begin{array}{l}\text { Livre de enxofre e compostos aromáticos, alto } \\
\text { número de cetanos, ponto de combustão apropriado, } \\
\text { excelente lubricidade, não tóxico e biodegradável. }\end{array}$
\end{tabular}

Ambientalmente benéfico Nível de toxicidade compatível ao sal ordinário, com diluição tão rápida quanto a do açúcar (Departamento de Agricultura dos Estados Unidos).

Menos poluente

Economicamente competitivo
Reduz sensivelmente as emissões de (a) partículas de carbono

(fumaça), (b) monóxido de carbono, (c) óxidos sulfúricos e (d) hidrocarbonetos policíclicos aromáticos

Complementa todas as novas tecnologias do diesel com desempenho similar e sem a exigência da instalação de uma infraestrutura ou política de treinamento

\begin{tabular}{|l|l|}
\hline $\begin{array}{l}\text { Reduz aquecimento } \\
\text { global }\end{array}$ & $\begin{array}{l}\text { O gás carbônico liberado é absorvido pelas } \\
\text { oleaginosas durante o crescimento, o que equilibra o } \\
\text { balanço negativo gerado pela emissão na atmosfera. }\end{array}$ \\
\hline $\begin{array}{l}\text { Economicamente } \\
\text { atraente }\end{array}$ & $\begin{array}{l}\text { Permite a valorização de subprodutos de atividades } \\
\text { agroindustriais, aumento na arrecadação regional de } \\
\text { ICMS, aumento da fixação do homem no campo e de } \\
\text { investimentos complementares em atividades rurais. }\end{array}$ \\
\hline Regionalização & $\begin{array}{l}\text { Pequenas e médias plantas para produção de } \\
\text { biodiesel, podem ser implantadas em diferentes }\end{array}$ \\
\hline
\end{tabular}


regiões do país, aproveitando a matéria prima disponível em cada local.

Fonte: (COSTA NETO et al., 2000)

O biodiesel produzido a partir do óleo de fritura se destaca pelo seu grande apelo ambiental. É muito comum, após a utilização de óleos vegetais no processo de fritura de alimentos, despejar esse resíduo em pias e ralos ou lançar diretamente em valas e esgotos. Como não há uma cultura de reciclagem desse material, nem mesmo uma obrigação normativa instituída pela legislação brasileira para uma correta destinação, esse óleo acaba alcançando o meio ambiente local, causando muitos distúrbios ambientais, além de impactos aos cofres públicos, no momento em que intervém para remediar o problema.

Uma vez presente nos sistemas de esgotos, o óleo residual tende a se juntar com materiais orgânicos, solidificando-se, causando entupimentos nas vias sanitárias. Tal quadro é propício para enchentes e acúmulo de pragas urbanas e vetores de doenças potencialmente fatais. Chegando aos mananciais, sua baixa solubilidade pode diminuir a superfície de contato entre o ar atmosférico e a água, acarretando uma diminuição da oxigenação do manancial e, consequentemente, causando um prejuízo para a vida. Da mesma forma, o óleo pode impedir a entrada de luz que alimenta os fitoplânctons desses aquíferos, alterando a cadeia alimentar do ecossistema. Ademais, o processo de decomposição desses rejeitos emite metano na atmosfera, um dos principais gases que causam o efeito estufa (FREITAS; BARATA; NETO, 2010).

Segundo Castellanelli et al. (2007), a reutilização do óleo de fritura na produção do biodiesel permite reduzir em $88 \%$ o volume desse rejeito, sendo que $2 \%$ desse valor consiste em matéria sólida; $10 \%$ consiste em glicerina e os $88 \%$ restantes formariam um éster com grande valor energético (biodiesel). Ao final do processo, obtém-se um biocombustível de boa qualidade e, ao mesmo tempo, recicla-se um resíduo que poderia provocar danos ao meio ambiente. 
Atualmente, o biodiesel brasileiro é obtido por meio de diversas matérias-primas como óleos vegetais, subprodutos da agropecuária e o óleo residual de fritura. Dentre estas, destaca-se a soja, com participação de $67,84 \%$ da produção nacional em 2018 , seguido da gordura bovina $(12,30 \%)$ e outros materiais graxos $(11,67 \%)$, conforme Figura 4.

Figura 5: Perfil nacional de matérias-primas consumidas para a produção de biodiesel - ano de 2018

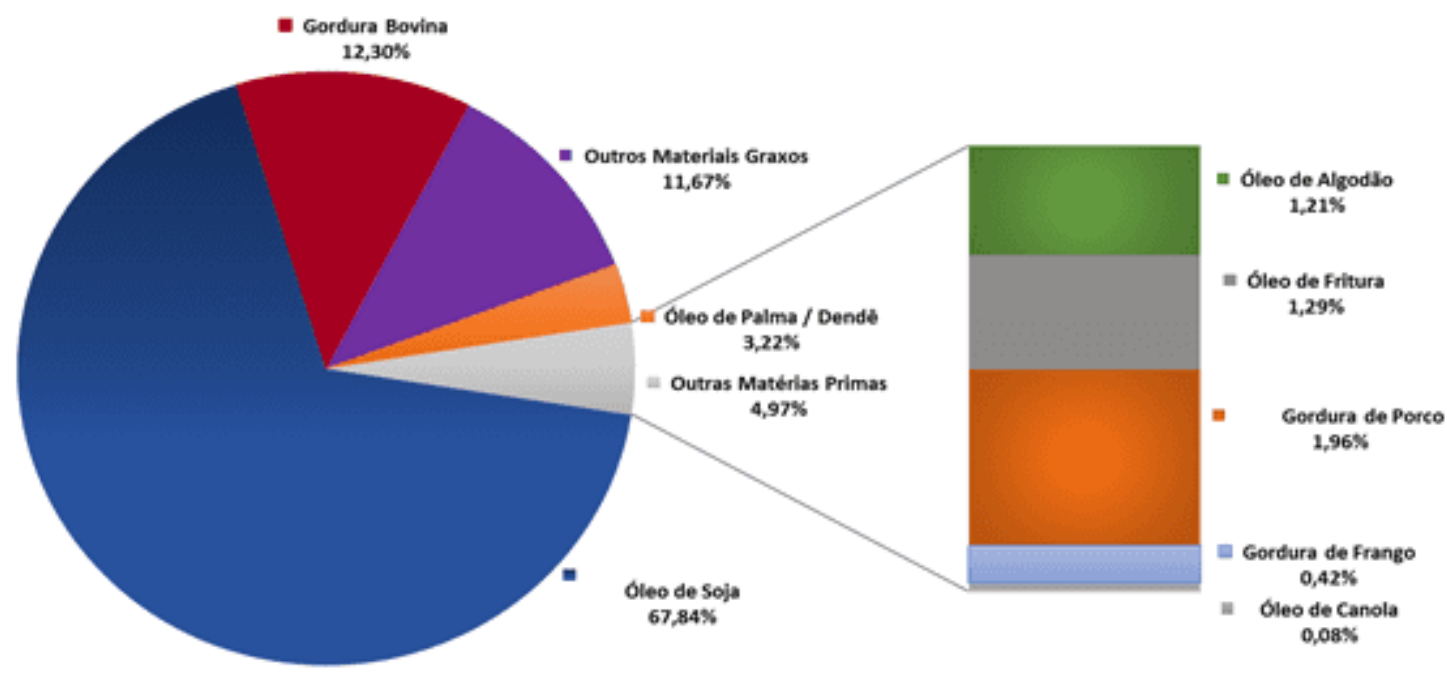

Fonte: ANP, 2019

A utilização do óleo de fritura como matéria-prima para a fabricação de biodiesel, apesar de muito tímida, tem variado pouco no Brasil nos últimos três anos. Dados da ANP $(2019)^{13}$ demonstra que, atualmente, este insumo tem baixa representatividade para a produção nacional de biodiesel, o que pode revelar um nicho ainda pouco explorado. Os dados da participação do óleo de fritura na produção do biodiesel nacional dos anos de 2017, 2018 e 2019 estão presentes na Figura 6, atualizados até o mês de setembro de 2019. 
Figura 6: Participação do óleo de fritura na produção do biodiesel brasileiro nos anos de 2017, 2018 e 2019 (dados atualizados até setembro de 2019)

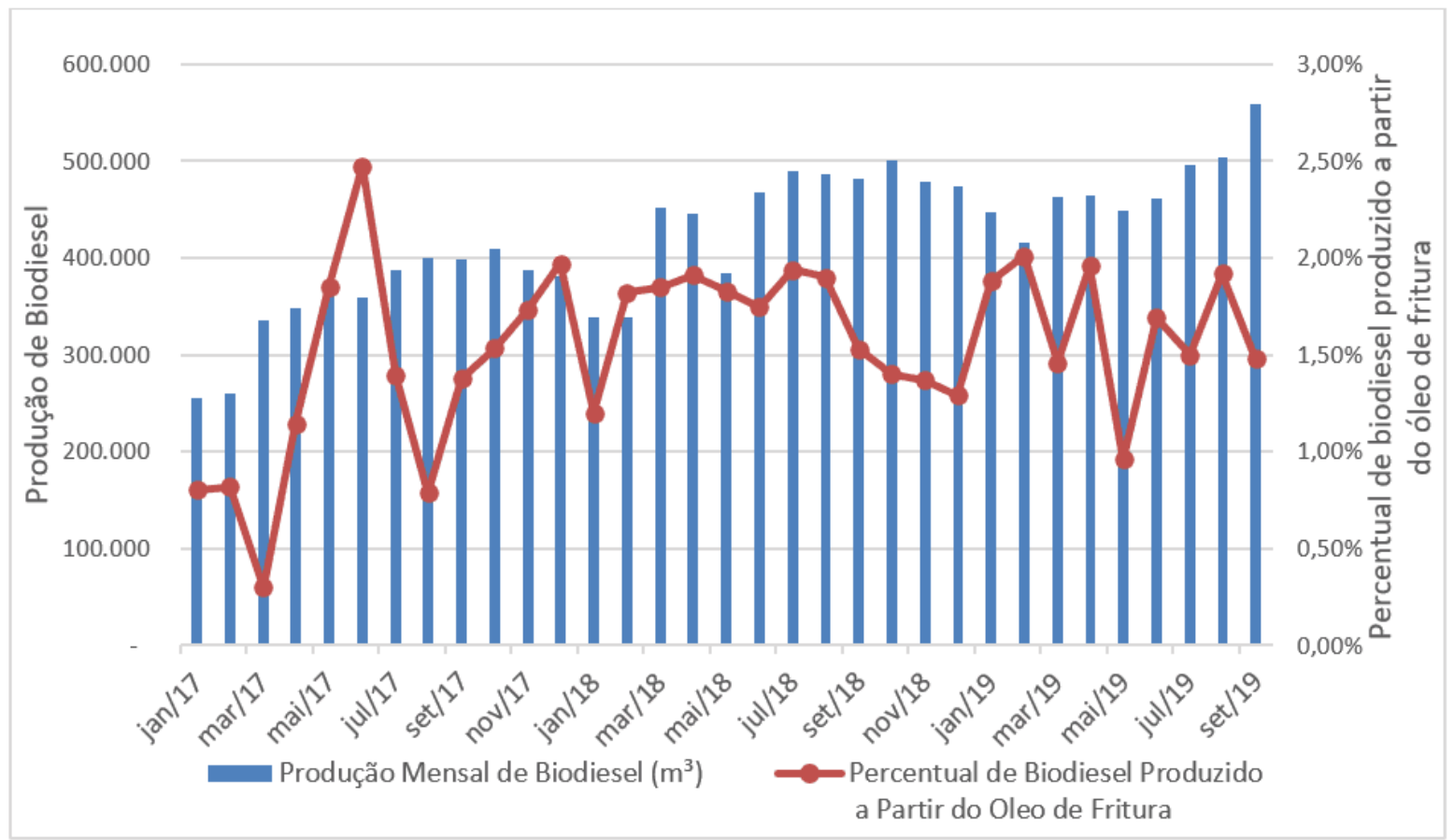

Fonte: ANP, 2019

A Figura 7 demonstra a quantidade de usinas de biodiesel no Brasil, distribuídas por estado/região, bem como a capacidade de produção autorizada pela ANP para cada estado produtor. É possível perceber que as regiões Sul e Centro-Oeste possuem maior participação na produção, contrastando com as regiões Norte e Nordeste. O estado de Alagoas não figura entre as Unidades Federativas que produzem biodiesel. 
Figura 7: Plantas de biodiesel autorizadas para a operação

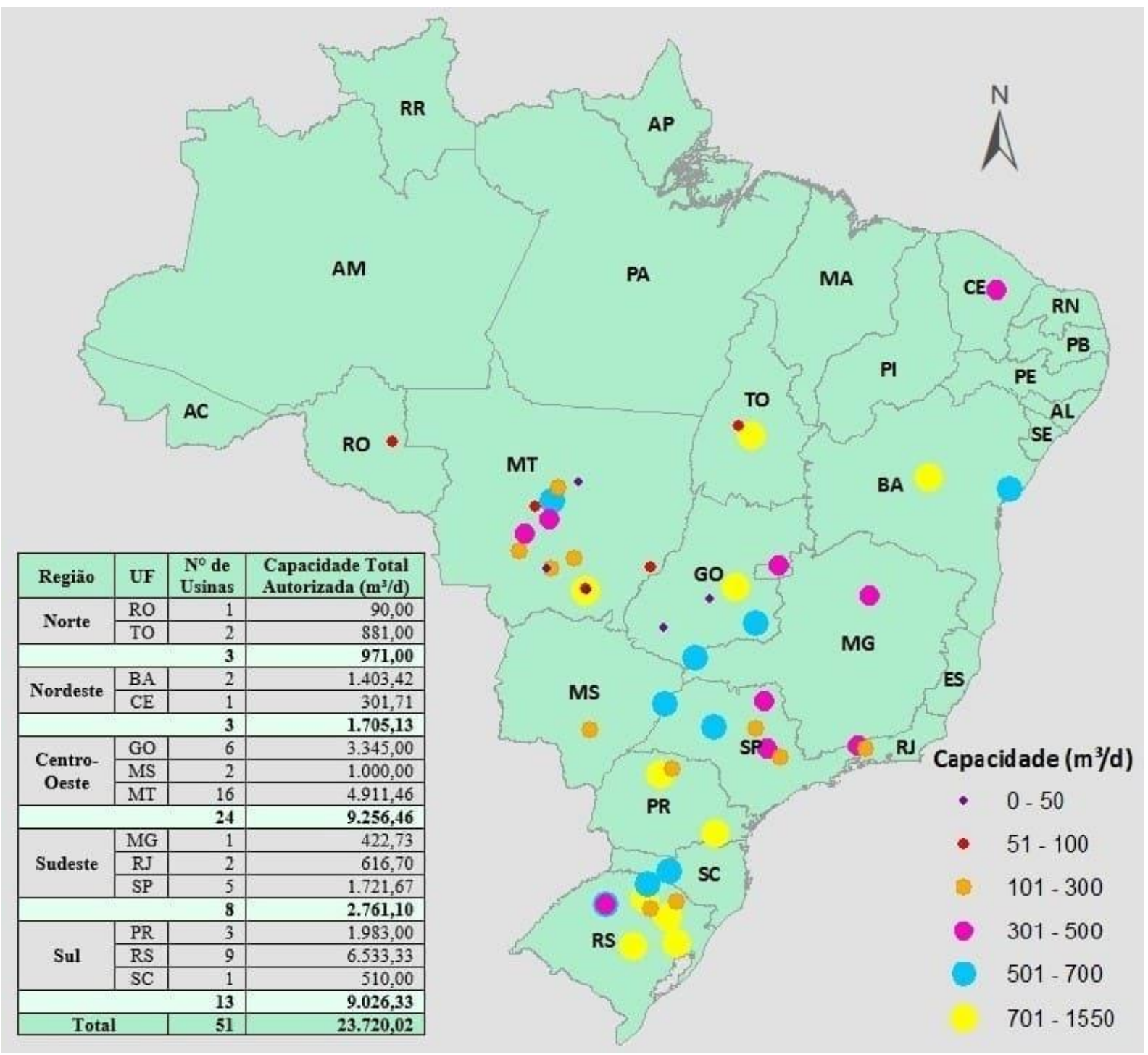

Fonte: ANP, 2019

Em termos econômicos, existem vários pesquisadores que defendem a utilização do óleo de fritura como matéria-prima para a obtenção do biodiesel. Segundo Casttellanelli et al (2007), estima-se que dois terços do preço final da produção do biodiesel derivem do custo da matéria-prima. Assim sendo, a produção desse biocombustível através da utilização do óleo residual de fritura traria um baixo custo, um produto final de boa qualidade e inúmeros benefícios ambientais. 
Seguindo a mesma linha, Chhetri et al (2008) confirma que uma das principais preocupações na produção do biodiesel é o preço da matéria-prima. Desta forma, a reutilização do óleo de fritura aumenta consideravelmente a viabilidade econômica da produção de biodiesel, destacando que esta é uma das opções mais econômicas para produzir o referido combustível.

Chistoff (2006) atesta a viabilidade do processo de produção do biodiesel através do óleo de fritura, via transesterificação etílica, e ressalta que o incentivo a formação de cooperativas e associações destinadas ao recolhimento desses óleos teria potencial para zerar o custo de aquisição deste mesmo resíduo.

Não obstante, Camargo e Carvalho (2014) observa que a obtenção do óleo residual para fins de produção do biodiesel necessita de uma logística bem estruturada e eficaz, capaz de arrecadar uma grande quantidade deste insumo. Isso permitiria uma maior economicidade ao processo, frente a outras matérias-primas.

Já Apolinário et al (2012) salienta que a glicerina, gerada como subproduto do processo de transesterificação, possui uma enormidade de aplicações, especialmente na indústria de produtos plásticos, cosméticos e farmacêuticos. Ela também está presente como componente químico de tintas, vernizes, detergentes e conservantes de bebidas e alimentos industrializados, entre outros.

\section{RESULTADOS E DISCUSSÃO}

Interpretando os dados do Beal (2018), percebe-se que há uma grande necessidade de se diversificar a matriz energética do estado, principalmente quando se leva em consideração o fato de haver uma dependência profunda dos derivados da cana-deaçúcar. Mesmo sendo uma fonte de energia renovável, o sucesso ano a ano da sacaricultura, como qualquer outra cultura agrícola comercializável, depende de uma série de fatores, muitos deles improváveis de serem controlados como o clima propício, capacidade de produção ou mesmo oferta e demanda do mercado, o que pode elevar o risco de uma recessão no setor e, por conseguinte, um eventual desabastecimento de energia. 
Apesar de Santos et al. (2007) ressaltar que há um contexto histórico muito intenso por detrás dessa influente predominância da cana-de-açúcar na economia alagoana, o que pode vir a ser um obstáculo para uma mudança governamental de pensamentos e atitudes, a diversidade energética deve ser colocada em primeiro plano, especialmente por ser um ponto que deve ser tratado como uma questão estratégica nas políticas públicas do estado.

Entendendo o iminente esgotamento das fontes de energia fósseis, a saber o petróleo e seus derivados, Branco (2013) aponta que a exploração de energias renováveis e ecológicas é uma via que deve ser incentivada. O biodiesel, por sinal, demonstra ser bastante promissor, especialmente por ter características muito semelhantes ao diesel mineral e advir de um bom número de matérias-primas, flexibilizando sua cadeia produtiva.

Ainda segundo Oliveira et al. (2008), o biodiesel é um combustível que possui muitas virtudes como ser livre de enxofre e compostos aromáticos, não tóxico, biodegradável, não exige uma adaptação do motor movido a diesel para ser utilizado e, no Brasil, de acordo com Finco e Doppler (2011), possui um conjunto de normas e leis que incentivam sua produção e lhe conferem um conceito de combustível promotor do crescimento socioambiental e da inclusão social.

Concernente à economia alagoana, apesar do IBGE (2019) apontar números que preveem uma recuperação, não parece surtir muitos efeitos no seu poder de empregabilidade $e$, atrelado ao fato do estado ainda não possuir uma usina de biodiesel, a possibilidade dessa implantação poderia contribuir para atenuar tanto a baixa oferta de empregos quanto a diversificação energética. Ademais, o biodiesel teria um grande potencial para abastecer principalmente o setor de transportes alagoano, o que, segundo a Figura 4, representa mais de um terço do todo o consumo do estado.

Quanto ao fato de se utilizar o óleo de fritura como matéria-prima para a produção desse biocombustível em Alagoas, o grande chamariz está na possibilidade de se utilizar, como insumo, um resíduo poluente que de outra sorte seria descartado no 
meio ambiente. Isso traria inúmeros benefícios a comunidade em geral, criando um impacto ambiental positivo, haja visto que haveria uma diminuição nos inúmeros problemas ocasionados pelo descarte incorreto desses óleos no ambiente, associado aos já aqui expostos benefícios da utilização do biodiesel (FREITAS; BARATA; NETO, 2010).

Em termos econômicos, o biodiesel de óleo de fritura tende a ter um custo de produção mais barato, em razão da farta disponibilidade em que é encontrado esse material e seu baixo valor agregado. Como o óleo de cozinha é bastante utilizado em quase todos os domicílios, a tendência é não haver maiores problemas na sua aquisição, inclusive com a possibilidade de ser obtido de forma gratuita, desde que montada uma eficiente rede de coleta e distribuição desse resíduo, valendo-se também da participação de governos e entidades afins. Não obstante, a glicerina gerada como derivada do biodiesel também poderia ser comercializada, agregando ainda mais valor a essa cadeia de produção.

Por fim, as empresas investidoras nesse mercado poderiam ser reconhecidas por todos como entidades promotoras do bem-estar do meio ambiente, impulsionando o marketing, produzindo energia limpa e renovável a partir de material reciclado, gerando lucros e empregos, o que seria de muito valor para toda a sociedade alagoana.

\section{CONCLUSÃO}

Os dados da matriz energética alagoana nos oferecem uma noção positiva em relação ao fato de uma parte considerável ser de origem renovável, porém nos mostra a alarmante falta de diversificação dessa energia. Dentre as várias alternativas, o biodiesel se mostra uma das melhores soluções, especialmente por ter, em primeiro lugar, características atraentes de redução dos níveis de poluição ambiental e, em segundo lugar, pelo fato de ter desempenho semelhante ao seu correspondente fóssil, podendo ser usado nos motores a diesel sem maiores problemas. Isso deve ser levado em consideração nesse cenário energético de Alagoas, principalmente quando 
se propõe o biodiesel como opção para o setor de transportes, o maior segmento demandante de energia do estado.

Por outro lado, a implantação de uma usina de biodiesel em Alagoas, por si só, já traria uma inovação também no meio mercadológico, possibilitando o estado desbravar um nicho comercial que hoje não é explorado, gerando empregos e renda, além de mitigar os impactos ao meio ambiente.

A escolha da matéria-prima para o desenvolvimento desse biocombustível também é um ponto importante nessa discussão. Em que pese as várias potenciais fontes disponíveis, olhando do ponto de vista econômico e levando em consideração que a aquisição de cada uma delas gera um custo considerável ao processo, a reutilização do óleo de fritura seria uma opção viável, especialmente por ter um potencial de ser adquirido gratuitamente, além de ser uma alternativa sustentável, considerando que estar-se-ia promovendo um descarte correto a este resíduo que, de outra forma, causaria inúmeros transtornos ambientais.

Finalmente, é mister ressaltar que o êxito desse processo passa, necessariamente, pela implantação de um eficiente sistema de coleta de óleos usados, uma realidade a qual o estado de Alagoas ainda não vivencia. A utilização de campanhas educativas, parcerias com entidades afins e mudanças na legislação a favor desse processo são alternativas que podem facilitar a criação deste cenário.

\section{REFERÊNCIAS}

ANP. Biodiesel. Disponível em: <http://www.anp.gov.br/biocombustiveis/biodiesel>. Acesso em: 1 nov. 2019a.

ANP. Dados Estatísticos. Disponível em: <http://www.anp.gov.br/dadosestatisticos>. Acesso em: 1 nov. 2019b.

APOLINÁRIO, F. D. B.; PEREIRA, G. DE F.; FERREIRA, J. P. Biodiesel e Alternativas para utilização da glicerina resultante do processo de produção de biodiesel. Revista 
de divulgação do Projeto Universidade Petrobras e IF Fluminense, v. 2, n. 1, p. 141-146, 2012.

ASTM. New Biodiesel Specifications Published by ASTM International. Disponível em: <https://www.astm.org/cms/drupal-7.51/newsroom/new-biodiesel-specificationspublished-astm-international>. Acesso em: 1 dez. 2019.

ÁVILA, T. SEPLAG. Disponível em: <http://www.seplag.al.gov.br/noticia/item/2379alagoas-e-o-unico-estado-a-retomar-patamar-economico-anterior-a-crise-de-2015>. Acesso em: 20 nov. 2019.

BEAL. Balanço Energético do Estado de Alagoas, 2018.

BRANCO, L.G.B. Biocombustíveis: Vantagens e Desafios. Revista Eletrônica de Energia - UNIFACS, v. 3, n. 1, p. 16-33, 2013.

BRASIL. MEDIDA PROVISÓRIA № 214, DE 13 DE SETEMBRO DE 2004. Disponível em: <http://www.planalto.gov.br/ccivil_03/_Ato2004-2006/2004/Mpv/214.htm>. Acesso em: 1 out. 2019.

CAMARGO, R. P. L.; CARVALHO, C. R. R. Estudos de Viabilidade Econômica da Utilização dos Óleos e Gorduras Residuais para Produção de Biodiesel no Brasil. Revista Processos Químicos, v. 8, n. 15, p. 39-48, 2014.

CASTELLANELLI, C. A. et al. Análise ambiental e econômica do biodiesel obtido por meio do óleo de fritura usado em praças de pedágio. Revista Ibero Americana de Estratégia, v. 6, n. 2, p. 165-173, 2007.

CHHETRI, A.; WATTS, K.; ISLAM, M. Waste Cooking Oil as an Alternate Feedstock for Biodiesel Production. Energies, v. 1, n. 1, p. 3-18, 2008.

CHRISTOFF, P. Produção de biodiesel a partir Do Óleo Residual De Fritura. Curitiba: Instituto de Tecnologia do Paraná, 2006. 
CONAB. Série Histórica das Safras. Disponível em: <https://www.conab.gov.br/infoagro/safras/serie-historica-das-safras>. Acesso em: 15 nov. 2019.

COSTA NETO, P. R. et al. Produção de biocombustível alternativo ao óleo diesel através da transesterificação de óleo de soja usado em frituras. Quimica Nova, v. 23, n. 4, p. 531-537, 2000.

DE SOUZA, V. H. A. et al. Um Panorama Do Biodiesel No Brasil E No Mundo: Esforços Para a Ampliação Do Setor E Desafios. Revista Augustus, v. 21, n. 41, p. 117-130, 2016.

DOMINGOS, A. K. Produção De Biodiesel Via Catálise Heterogênea. Rio de Janeiro: Universidade Federal do Rio de Janeiro, 2010.

FAJARDO., C. A. G.; GUERRERO-ROMERO, A.; SIERRA, F. E. Biodiesel Feedstocks and Processing Technologies. Colombia: InTech, 2011. v. 3

FAZENDA, S. DA. Balanço geral, 2017.

FINCO, M. V. A.; DOPPLER, W. The Brazilian Biodiesel Program and Regional Development : Cases From Northern Brazil. Revista do Desenvolvimento Regional, v. 16, n. 3, p. 215-241, 2011.

FREITAS, C. F. DE; BARATA, R. A. DA R.; NETO, L. DE S. M. Utilização do óleo de cozinha usado como fonte alternativa na produção de energia renovável, buscando reduzir os impactos ambientais. XXX Encontro Nacional De Engenharia De Produção. Anais...São Paulo: 2010

IBGE. Pesquisa Nacional por Amostra de Domicílios. Disponível em: $<$ https://sidra.ibge.gov.br/pesquisa/pnadct/tabelas>. Acesso em: 1 out. 2019.

M. M. PINHO, D.; A. Z. SUAREZ, P. From Peanut Oil to Biodiesel- History and Brazilian Policyfor the Energetic Use of Fats and Oils. Revista Virtual de Química, v. 9, n. 1, p. 39-51, 2017. 
OLIVEIRA, F. C. C.; SUAREZ, P. A. Z.; SANTOS, W. L. P. Biodiesel: Possibilidades e Desafios. Química Nova na Escola, n. 28, p. 3-8, 2008.

PARENTE, E. J. DE S. BIODIESEL: Uma Aventura Tecnológica num País Engraçado. Fortaleza: Tecbio, 2003.

PLÁ, J. A. Perspectivas do biodiesel no Brasil. Indic. Econ. FEE, v. 30, n. 2, p. 179190, 2002.

RAMOS, L. P. et al. Biodiesel: Um projeto de sustentabilidade econômica e sócioambiental para o Brasil. 2008. Revista Biotecnologia Ciência e Desenvolvimento, n. $31^{\mathrm{a}}, 2003$.

SABESP.

em:

<http://site.sabesp.com.br/site/interna/Default.aspx?secaold=115\%0Ahttp://site.sabe sp.com.br/site/interna/Default.aspx?secaold=115>. Acesso em: 18 out. 2019.

SANTOS, A. L. DA S.; PEREIRA, E. C. G.; ANDRADE, L. DE H. C. A Expansão Da Cana-De-Açúcar No Espaço Alagoano E Suas Conseqüências Sobre O Meio Ambiente E a Identidade Cultural. Revista de Geografia Agrária, v. 2, n. 4, p. 19-37, 2007.

SILVA, O. C. Análise do aproveitamento econômico e energético do óleo de palma na GB na perspectiva do desenvolvimento sustentável. São Paulo: Universidade de São Paulo, 1997.

Enviado: Janeiro, 2020.

Aprovado: Abril, 2020. 